and other points will be discussed in our memoir on the London femora now at press. I write at present at this length merely to indicate that in suggesting to Dr. Lee to illustrate her tables on Dr. Parsons's material, I had in view many observational points which Dr. Parsons, like not a few of our English critics, considers we have made no attempt to appreciatebeing "mere mathematicians." KarL PEARSON.

Galton Laboratory, University of London.

\section{A Remarkable Dry Fog in the East Indian Archipelago.}

THE observations made on Ben Nevis upon the transparency of the air have shown very clearly that with increasing relative humidity the transparency is diminishing, a consequence of the increasing volume of the light-scattering particles, from which it may be concluded that the particles are of hygroscopic character.

The influence of humidity on the size of these particles was obvious in a very striking way in the dense dry fog that towards the end of the dry monsoon of 1914 spread out over the East Indian archipelago, causing much trouble to navigation.

A short description of this phenomenon is given below. The fog had a grey colour, and was most intense in the month of September, and especially in October, and disappeared when the rains fell. In its most typical form it appeared in Sumatra, in the neighbourhood of Ambon and the islands to the southeast.

In Sumatra it was observed to the north as far as Medan (Deli), the Karo plateau near the Toba lake and Tapanoeli, to the south as far as Benkoelen and the highlands of Kerintji. It was not observed in the open ocean outside the Mentawei Islands.

In the morning the sun was not visible before eight o'clock, when it appeared as a dim red disc. Objects in general were barely visible at 500 metres' distance, and on the thickest days invisible within half this distance; the mountains had disappeared entirely from view.

In Ambon the sea was sometimes invisible from the lighthouse, which is situated close to the shore, and 140 metres above the sea. Also in the straits between Sumatra and Borneo, and the west and east coast of Borneo, the fog was very thick, and though in somewhat less degree it was also observed in the northern part of the Strait of Makasser, on the north coast of New Guinea (in these regions, however, it was more or less mixed up with smoke from forest fires, which caused local intensification), on Sumatra's west coast north of Padang and Malakka Strait.

Though in the other parts of the archipelago the transparency of the air was greater, it was not quite clear, on account of the blue haze that is common to the dry season.

A similar phenomenon (described by Dr. van Bemmelen, Meteorl. Zeitschr., August, I905), perhaps still more intense, was observed in the very dry year r9o2; it then extended to the southern part of the China Sea and to the south-east so far as the Tanimber Islands, the region of greatest intensity being about the same as in I9I4. It was also reported from the abnormally dry years $1885,1888,189 \mathrm{I}$, and 1896. In Karimata Strait it is a common phenomenon.

Now it is very remarkable that the southern boundary of the fog coincides rather closely with a well-defined line, that separates the region of practically no rainfall from that of greater humidity where light rains begin to appear. In I9I4 this line ran in the months of September and October over the southeast point of Sumatra, along Billiton and Borneo's NO. 2365 , VOL. 94$]$ south coast, through Makassar Strait, along North Celebes, and south-eastwards along the south coast of New Guinea, Ambon, and the region south-east of it lying as an oasis of light rainfall in the dry region.

From this it is evident that it is the hygroscopic particles that form the blue haze in the south-eastern part of the archipelago, which, entering into moister regions and increasing their radius, give rise to the appearance of the grey fog.

Physical laws fully account for the fact that the fog is a mere intensification of the haze, though the rather fast transition of the light blue haze to the much thicker grey fog gives the impression of a new phenomenon springing into existence.

So long as the particles are much smaller than the wave-length, the intensity of the scattered light in relation to that of the light falling upon it, may be represented by $\mathrm{I}=a r^{6} / \mathrm{R}^{2} \lambda^{4}$, when $r$ is the radius of the particle, $R$ the distance from the observer, and $\lambda$ the wave-length. When $r$ is increasing, the ordinary reflection ultimately appears, and $I=\beta r^{2} / R^{2} \lambda^{0}$.

From the method of dimensions may be concluded (conf. Rayleigh, "Theory of Sound," II., p. 152), I being a simple ratio and $\alpha$ and $\beta$ passing gradually and rather slowly into each other as $r$ increases, that as the exponent $(n)$ of $\lambda$ is changing from 4 to $o$ the exponent $(m)$ of $r$ changes from 6 to 2 . Therefore, so long as $n$ is large enough to produce a colouring of the haze, $m$ will cause a very rapid increase of the intensity of the scattered light, which may account for the rather sudden change of the blue haze to the grey fog.

It is not in the first place the greater number of particles that account for the difference between the transparency of the air in the dry and wet season, but their hygroscopic character. On December 23, 1914, when the wet season had already set in, I counted with Aitken's apparatus at Batavia 50,000 particles in I cub. cm., the relative humidity being 84 per cent., and no trace of haze was to be seen. However, on the Ardjoeno (at 2500 metres' height) on October 29 , towards the end of the dry season, their number was only 1800 in $\mathrm{I}$ cub. $\mathrm{cm}$., and notwithstanding the humidity was only 40 per cent., the surroundings were enveloped in an intense blue haze. Especially these very hygroscopic particles, when entering moister regions, will be susceptible to a strong increase of volume, and therefore will be the principal producers of the fog.

When we put the question where those highly hygroscopic particles come from that are responsible for the phenomenon described above, it may be remarked that for the greater part they do not form during the short journey of the trade wind over the archipelago. This takes only a few days, whereas the fog appears after many months of excessive drought. Two causes may be mentioned to which they owe their existence, viz., burning processes in Australia, which are also most frequent after longprolonged droughts; and, secondly, which I take for the greater influence, the formation from the components of the air, ozone, nitrogen, etc., during the slow descending movement in the Australian anticyclone, in which the air probably takes several months to reach the layers near the surface of the earth.

Batavia, January, I9ז5.

C. BRAAK.

\section{A Penalty on Research.}

IF Sir Wm. Ramsay was refused a rebate of the duty on alcohol I could scarcely expect better treatment. Nevertheless, I should like to add to his protest, and complaint After a correspondence lasting 